\title{
Correction: Liu, L., et al. Spatiotemporal Variation of Drought and Associated Multi-Scale Response to Climate Change over the Yarlung Zangbo River Basin of Qinghai-Tibet Plateau, China. Remote Sensing $2019,11,1596$
}

\author{
Hao Li ${ }^{1,2} \oplus$, Liu Liu ${ }^{1,2}, * \mathbb{C}$, Baoying Shan ${ }^{1,2}$, Zhicheng $X u^{3,4,5}$, Qiankun Niu 1,2, Lei Cheng ${ }^{3,4,5}$, \\ Xingcai Liu ${ }^{6}(\mathbb{D})$ and Zongxue $\mathrm{Xu}^{7,8}$ \\ 1 College of Water Resources and Civil Engineering, China Agricultural University, Beijing 100083, China; \\ lihao@cau.edu.cn (H.L.); shanby@cau.edu.cn (B.S.); s20193091589@cau.edu.cn (Q.N.) \\ 2 Center for Agricultural Water Research in China, China Agricultural University, Beijing 100083, China \\ 3 State Key Laboratory of Water Resources and Hydropower Engineering Science, Wuhan University, \\ Wuhan 430072, China; zhichengxu@whu.edu.cn (Z.X.); Lei.Cheng@whu.edu.cn (L.C.) \\ 4 Hubei Provincial Collaborative Innovation Center for Water Resources Security, Wuhan 430072, China \\ 5 Hubei Provincial Key Lab of Water System Science for Sponge City Construction, Wuhan University, \\ Wuhan 430072, China \\ 6 Institute of Geographic Sciences and Natural Resources Research, Chinese Academy of China, \\ Beijing 100101, China; xingcailiu@igsnrr.ac.cn \\ 7 College of Water Sciences, Beijing Normal University, Beijing 100875, China; zxxu@bnu.edu.cn \\ 8 Beijing Key Laboratory of Urban Hydrological Cycle and Sponge City Technology, Beijing 100875, China \\ * Correspondence: liuliu@cau.edu.cn; Tel.: +86-10-62737236; Fax: +86-10-62736533
}

Received: 5 December 2019; Accepted: 13 December 2019; Published: 18 December 2019

The authors wish to make the following corrections to this paper [1]:

1. On page 9, line 2, the word "significance" should be "confidence".

2. During the minor revision process, it was suggested that we improve the quality of Figure 9a-c with higher resolution images. Due to carelessness, we inserted Figure 9c as Figure 9a into the manuscript. What is worse, we did not find this mistake during proofreading; thus, please replace Figure 9a:

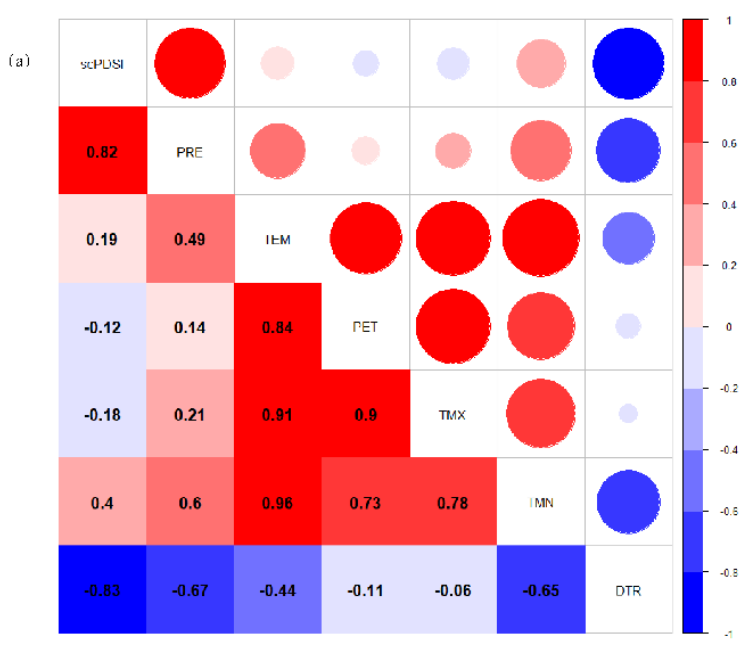


with

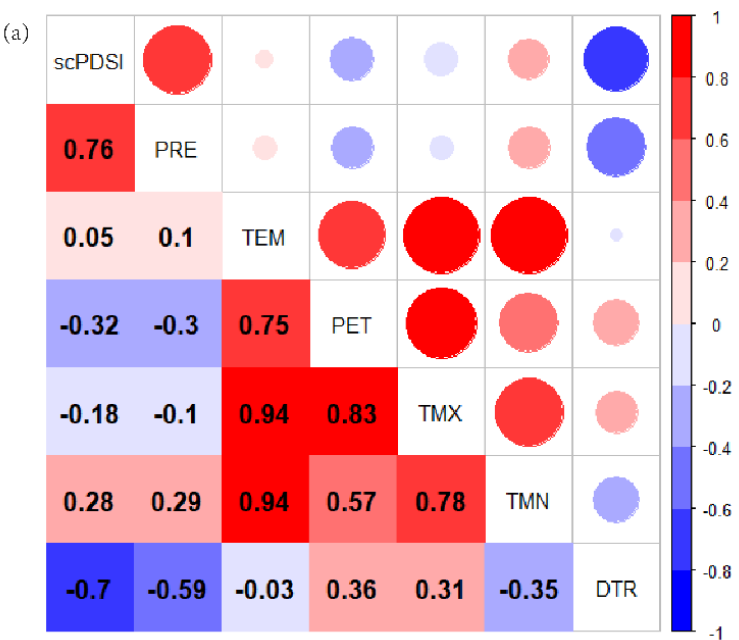

3. Due to the wrong legend, replace Figure 5:

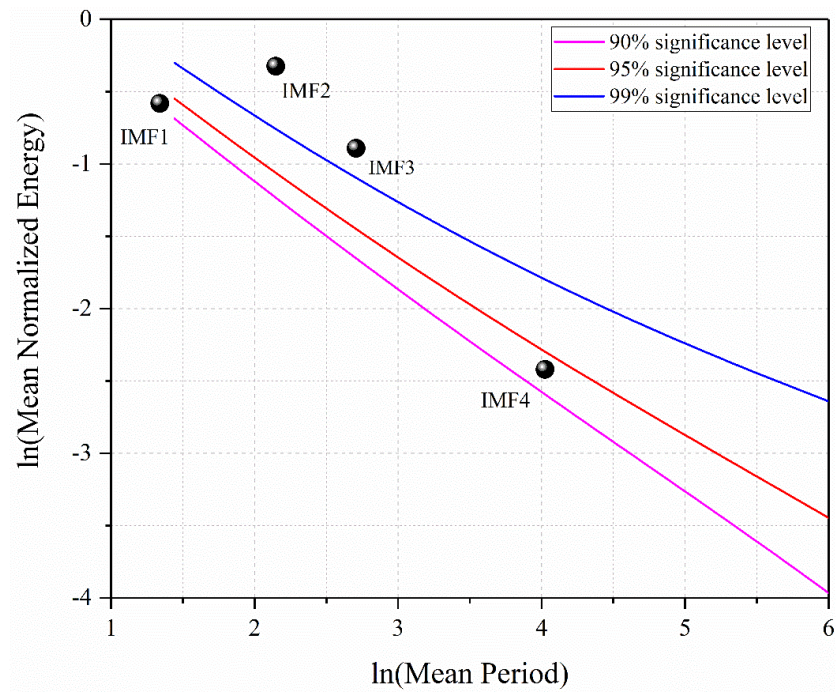

with

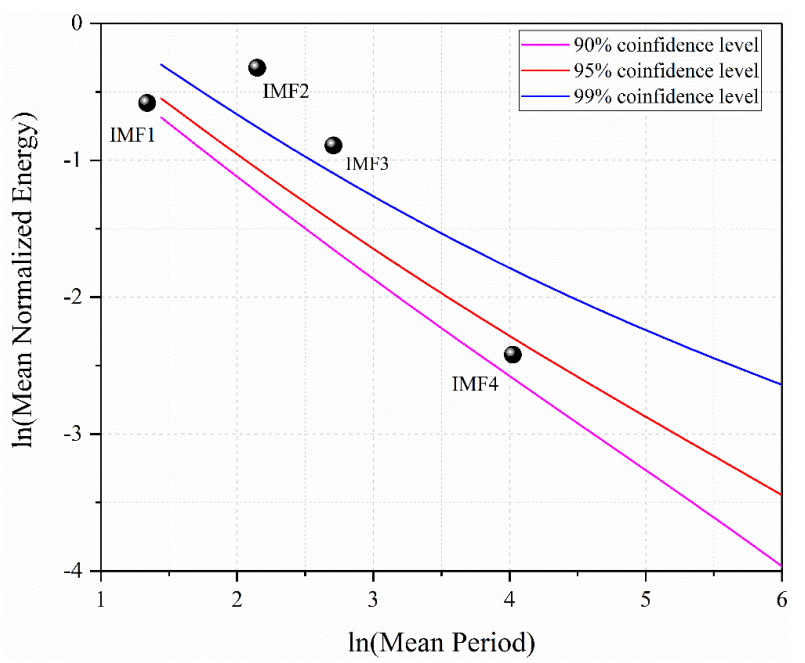


4. Due to a spelling mistake, replace Table 2:

\begin{tabular}{cccccc}
\hline & IMF1 & IMF2 & IMF3 & IMF4 & Trend \\
\hline Period/yr & 3 & 9 & 15 & 56 & \\
Contribution/\% & 26.4 & 28.9 & 21.3 & 7.8 & 15.6 \\
Significance & $90 \%$ & $99 \%$ & $99 \%$ & $90 \%$ & \\
\hline
\end{tabular}

with

\begin{tabular}{cccccc}
\hline & IMF1 & IMF2 & IMF3 & IMF4 & Trend \\
\hline Period/yr & 3 & 9 & 15 & 56 & \\
Contribution/\% & 26.4 & 28.9 & 21.3 & 7.8 & 15.6 \\
Confidence level & $90 \%$ & $99 \%$ & $99 \%$ & $90 \%$ & \\
\hline
\end{tabular}

These changes have no material impact on the conclusions of our paper. The authors would like to apologize for any inconvenience caused to the readers by these changes.

\section{Reference}

1. Li, H.; Liu, L.; Shan, B.Y.; Xu, Z.C.; Niu, Q.K.; Cheng, L.; Liu, X.C.; Xu, Z.X. Spatiotemporal Variation of Drought and Associated Multi-Scale Response to Climate Change over the Yarlung Zangbo River Basin of Qinghai-Tibet Plateau, China. Remote Sens. 2019, 11, 1596. [CrossRef]

(C) 2019 by the authors. Licensee MDPI, Basel, Switzerland. This article is an open access article distributed under the terms and conditions of the Creative Commons Attribution (CC BY) license (http://creativecommons.org/licenses/by/4.0/). 